\title{
Adverse Selection in Community Based Health Insurance among Informal Workers in Bangladesh: An EQ-5D Assessment
}

\author{
Sayem Ahmed 1,2,*(1), Abdur Razzaque Sarker ${ }^{1,3}$, Marufa Sultana ${ }^{1,4}$, Sanchita Chakrovorty ${ }^{1,5}$, \\ Md. Zahid Hasan ${ }^{1}$ (D), Andrew J. Mirelman ${ }^{6}$ (D) and Jahangir A. M. Khan ${ }^{1,2,7}$ \\ 1 Health Economics and Financing Research Group, Health Systems and Population Studies Division, \\ Bangladesh (icddr,b), Dhaka 1212, Bangladesh; arazzaque@icddrb.org (A.R.S.); marufa@icddrb.org (M.S.); \\ scakrov@purdue.edu (S.C.); md.zahid@icddrb.org (M.Z.H.); Jahangir.Khan@lstmed.ac.uk (J.A.M.K.) \\ 2 Health Economics and Policy Research Group, Department of Learning, Informatics, Management and \\ Ethics (LIME), Karolinska Institutet, SE-171 77 Stockholm, Sweden \\ 3 Department of Management Science, University of Strathclyde, Glasgow G1 1XQ, UK \\ 4 Faculty of Health, Deakin University, Melbourne, VIC 3125, Australia \\ 5 Department of Agriculture Economics, Purdue University, IN 47907, USA \\ 6 Centre for Health Economics, University of York, York YO10 5DD, UK; andrew.mirelman@york.ac.uk \\ 7 Department of Clinical Sciences, Liverpool School of Tropical Medicine, Liverpool L3 5QA, UK \\ * Correspondence: sayemahmed@icddrb.org or sayem.ahmed@ki.se; Tel.: +880-191-252-2643; \\ Fax: $+880-2881-1568$
}

Received: 15 November 2017; Accepted: 29 January 2018; Published: 31 January 2018

\begin{abstract}
Community-based Health Insurance (CBHI) schemes are recommended for providing financial risk protection to low-income informal workers in Bangladesh. We assessed the problem of adverse selection in a pilot CBHI scheme in this context. In total, 1292 (646 insured and 646 uninsured) respondents were surveyed using the Bengali version of the EuroQuol-5 dimensions (EQ-5D) questionnaire for assessing their health status. The EQ-5D scores were estimated using available regional tariffs. Multiple logistic regression was applied for predicting the association between health status and CBHI scheme enrolment. A higher number of insured reported problems in mobility $(7.3 \% ; p=0.002)$; self-care $(7.1 \% ; p=0.000)$ and pain and discomfort $(7.7 \% ; p=0.005)$ than uninsured. The average EQ-5D score was significantly lower among the insured (0.704) compared to the uninsured (0.749). The regression analysis showed that those who had a problem in mobility (m 1.25-2.17); self-care (OR $=2.29 ; 95 \%$ CI: $1.62-3.25)$ and pain and discomfort (OR $=1.43 ; 95 \% \mathrm{CI}$ : $1.13-1.81)$ were more likely to join the scheme. Individuals with higher EQ-5D scores (OR $=0.46$; 95\% CI: 0.31-0.69) were less likely to enroll in the scheme. Given that adverse selection was evident in the pilot $\mathrm{CBHI}$ scheme, there should be consideration of this problem when planning scale-up of these kind of schemes.
\end{abstract}

Keywords: adverse selection; community based health insurance; EQ-5D

\section{Introduction}

Out-of-pocket (OOP) healthcare payment is the predominant financing mechanism in many low- and middle-income countries (LMICs) [1]. It is a source of $48 \%$ of total healthcare expenditure in low-income countries [2]. This high reliance on OOP healthcare payment results in catastrophic healthcare expenditure and impoverishment in LMICs [2]. The World Health Organization suggested increasing dependency on innovative prepayment healthcare financing mechanisms with the provision of risk pooling for mitigating this problem [3]. Considering the limited revenue generated through 
taxation in low- and middle-income countries (LMICs), community-based health insurance (CBHI) schemes are a potential source of financing healthcare in these countries [1,4,5].

In Bangladesh, around $67 \%$ of the healthcare costs are borne by the OOP payments which result in high catastrophic health expenditures (16.5\%) among the poor [6,7]. To reduce this burden, the government of Bangladesh adopted its first-ever healthcare financing strategy in 2012 [8]. In this strategy, CBHI schemes are recommended for providing financial risk protection for low-income informal workers in Bangladesh.

CBHI schemes have rapidly grown over the last two decades as a health financing tool in LMICs where other insurance (e.g., government financed) is absent or may not be feasible [9]. Development actors are increasingly considering CBHI as an instrument that can enable easy access to quality healthcare in an affordable way [10]. The ultimate aims of such schemes are to facilitate access to healthcare and increase financial protection against the huge burden of OOP expenditure [11].

In most of the CBHI schemes, there is a chance of information asymmetry between the insurer and the insured. In particular, potential members know their disease risk levels better than the insurers. Therefore, high-risk members are able to purchase insurance at a lower premium than their disease risk would imply since the premium is fixed based on the average disease risk of the potential members and willingness-to-pay which is known as adverse selection [12]. In CBHI schemes, membership is voluntary in nature. However, several studies reported that such membership can cause adverse selection in these schemes $[9,13,14]$. In the presence of adverse selection, the financial sustainability of such schemes become vulnerable [15].

A large body of literature addressed the problem of adverse selection in cases of employer-sponsored or publicly managed insurance schemes [9]. However, limited studies have analyzed such problems in CBHI schemes in LMICs. The evidence reported both types of results; absence and presence of adverse selection. A study in China reported the adverse selection in the Rural Mutual Health Care [14]. Noterman et al., 1995 found adverse selection among women in their reproductive age under a prepayment scheme with coverage for hospitalization [16]. Dror et al., 2005 reported the absence of adverse selection in the Micro Health Insurance Units in the Philippines by assessing morbidity between insured and uninsured [17]. A similar result was found in a study conducted by De Allegri et al., 2006 for the CBHI scheme in Burkina Faso. Parmar et al., 2012 reported of having week evidence of adverse selection in a CBHI scheme in rural Africa $[9,18]$.

Since 2012, when the government of Bangladesh recommended CBHI schemes as a mechanism of healthcare financing for covering informal worker [8], there has been a growing interest in these types of schemes from policymakers, development partners, and health program implementers. In this context, it is important to analyze the presence of adverse selection to facilitate more effective health planning. In Bangladesh, there are no studies on whether adverse selection is a problem in CBHI schemes. We aim to examine this issue in a pilot CBHI scheme among the informal workers in Bangladesh.

\section{Materials and Methods}

\subsection{CBHI Scheme}

A CBHI scheme comprising a group of informal workers was implemented through forming a labor cooperative organization. The enrolment in the CBHI scheme was voluntary and the organization engaged in a number of marketing interventions (such as group meetings, and individual counseling by marketing staff) to enroll members in the scheme. Under the membership package for an informal worker, the other members of his/her household were considered as beneficiaries. A brief description of the CBHI scheme under this study is presented below.

Target population: Informal workers with low income and their household members in Chandpur sub-district (comprising urban and rural areas) of Bangladesh were the target population of this scheme.

Implementation entity: Labor Association for Social Protection, a cooperative organization, under the Ministry of Local Government and Rural Development was the main implementation entity. 
Beneficiaries: Up to six members of each household were entitled to health benefits for one membership card. The children under 5 were automatically enrolled in the scheme and not counted under the beneficiary limit.

Benefits package: The benefits package includes both health (e.g., discounted consultation, medicine, diagnostic test, and hospitalization) and non-health benefits (e.g., savings opportunity and technical training). The benefits package of the scheme is presented in Table 1.

Table 1. The benefits package of the CBHI scheme.

\begin{tabular}{|c|c|}
\hline Services & Co-Payment/Description * \\
\hline \multicolumn{2}{|l|}{ Health benefits } \\
\hline General practitioner (GP) Consultation & $30 \mathrm{BDT}($ Market price $=300 \mathrm{BDT})$ \\
\hline Medicine & $20 \%$ discount from maximum retail price \\
\hline Diagnostic tests & $50 \%$ discount on market price \\
\hline Specialist doctor consultation & $100 \mathrm{BDT}($ Market price $=500 \mathrm{BDT})$ \\
\hline Hospitalization & Maximum 4000 BDT per household per year \\
\hline Periodic satellite clinics in remote rural areas & Free of charge \\
\hline \multicolumn{2}{|l|}{ Non-health benefits } \\
\hline Savings opportunity & $\begin{array}{l}\text { - Each member/household could save minimum } 10 \text { BDT and } \\
\text { maximum } 100 \text { BDT per week per household }\end{array}$ \\
\hline Training programs & $\begin{array}{l}\text { - } 3 \text { months computer training for student member of the } \\
\text { household with a cost } 1200 \text { BDT (market price }=4500 \text { BDT) } \\
6 \text { months sewing training for female workers (free of charge) }\end{array}$ \\
\hline
\end{tabular}

$* 1$ USD $=77.72$ BDT [19].

Premium: The premium was 600 BDT (7.72 USD) per household per year which is $2.68 \%$ of the informal worker annual income 22,352 BDT (287.60 USD) [20].

\subsection{Study Design}

A quasi-experimental approach was employed to examine the differences in health status among those who joined the CBHI scheme (insured) and those who did not (uninsured). The uninsured had similar observable characteristics through matching on age, gender, residence, and household composition (e.g., presence of a child, elderly, and number of reproductive-aged women).

\subsection{Study Population and Sample}

This study was conducted in Chandpur Sadar Upazila (sub-district). It consists of 9 Unions (areas under sub-district) and the CBHI scheme was offered in 7 of them. We performed a cross-sectional survey of 1292 households (646 insured and 646 uninsured) from these 7 Unions during April-June 2014.

\subsection{Data Collection}

The household members aged 18 and above with involvement in household economic activities and decision making were selected as respondents for this study considering their availability for interview. We explained the study objectives to the respondents before interviewing them. We only interviewed individuals who provided informed written consent.

The respondents were interviewed using a pre-tested structured questionnaire. Face-to-face interview with respondents were conducted using the Bengali version of the EuroQuol-5 dimensions (EQ-5D) instrument. In addition, we collected demographic characteristics of individual members and households.

\subsection{Health Status Measurement}

The health status of study participants was estimated using the EQ-5D instrument. EuroQol group, a European-based researchers, developed the instrument to estimate health status score based on the 
individual responses [21]. This instrument contains two measurement parts. The first part defines the self-reported general state of health with five dimensions (mobility, self-care, usual activities, pain/discomfort, and anxiety/depression) which is known as the descriptive part. Each of these dimensions has three levels (no problems, some problems, and severe problems). The second part contains a self-reported visual analog scale (VAS) scale of $20 \mathrm{~cm}$ length. The individuals are asked to mark anywhere on the scale based on how well they feel about their health state today. In order to obtain health state scores, the scale has endpoints of 100 and 0 , where 100 indicates the "best imaginable health state" and 0 indicates the "worst imaginable health state" [22]. In this study, we used a Bengali version of the ED-5D instrument available for Bangladesh to estimate the individual's health status.

The EQ-5D index tariff assigns a single index value for all hypothetical health states identified by the EQ-5D instrument. The assigned values are estimated using a scale of 0 to 1 , where 0 represents dead and 1 represents perfect health. The values can be negative (up to -0.59) in cases of severely detrimental health conditions [23]. We used a Thailand based regional tariff in the absence of any such weights in Bangladesh context.

The individual response of having any problem (reported levels 2 and 3) in each of the EQ-5D dimension was calculated for the insured group and corresponding uninsured group. $t$-Tests were used to identify statistical significance of the difference in health state scores, demographic characteristics, and the VAS score between the groups. Chi-square tests were used to see the association between household size and insurance status. We used STATA version 13.0 (StataCorp. LLC, College Station, TX, USA) for conducting statistical analysis and adopted $p$-value of 0.05 or below as the statistically significant level.

\subsection{Econometric Analysis}

Multiple logistic regression models were used to predict the association between CBHI scheme enrolment and health status. We included five dimensions from the EQ-5D instrument and estimated scores as explanatory variables in separate models since these variables are moderately correlated (variance inflation factor from 1 to 3). The CBHI scheme enrollment was the dependent variable in each model. Demographic and household characteristics (e.g., age, gender, and household size) were included as control variables in each model. The models were specified as follows,

$$
\operatorname{logit}\left(Y_{i}\right)=\beta_{1} X_{1 i}+\beta_{2} X_{2 i}+\beta_{3} X_{3 i}+\ldots+\varepsilon_{i}
$$

where, $Y_{i}=$ CBHI enrollment $\left(1=\right.$ yes, $0=$ No), $X_{1}, X_{2}, X_{3} \ldots$ are explanatory variables, $\beta_{1}, \beta_{2}, \beta_{3} \ldots$ represent the estimated coefficients and $\varepsilon_{\mathrm{i}}$ is the random error term of the model. The adjusted odds ratios were estimated as an exponential of the coefficient. The $95 \%$ confidence intervals of adjusted odds ratios are presented.

\section{Results}

Table 2 presents the demographic and socioeconomic characteristics of the respondents. The results showed that most of the participants were an adult (aged less than 60 years) in both insured (95.8\%) and uninsured (95.5\%) group. In the insured group, 51.7\% were female and $48.3 \%$ were male and in the uninsured group $56.0 \%$ were female and $44.0 \%$ were male. Household size was larger in the insured group ( $52.6 \%$ had 6 or more members) compared to the uninsured group (30.3\% had 6 or more members). There was no significant difference in the background characteristics between the insured and uninsured group respondents other than the household size (Table 2). 
Table 2. Background characteristics.

\begin{tabular}{|c|c|c|c|}
\hline \multirow{2}{*}{ Characteristics } & Insured $(N=646)$ & Uninsured $(N=646)$ & \multirow{2}{*}{$p$-Value } \\
\hline & $\%(95 \% \mathrm{CI})$ & $\%(95 \% \mathrm{CI})$ & \\
\hline \multicolumn{4}{|l|}{ Age group } \\
\hline Adult $(<60)$ & 95.8 (93.9-97.1) & $95.5(93.6-96.9)$ & $0.780^{\mathrm{a}}$ \\
\hline Elderly $(60+)$ & $4.3(2.9-6.0)$ & $4.5(3.1-6.4)$ & \\
\hline \multicolumn{4}{|l|}{ Gender } \\
\hline Female & $51.7(47.8-55.5)$ & $56.0(52.2-59.8)$ & $0.120^{\mathrm{a}}$ \\
\hline Male & $48.3(44.5-52.2)$ & $44.0(40.2-47.8)$ & \\
\hline \multicolumn{4}{|l|}{ Household size } \\
\hline Fewer than 4 members & $6.8(5.1-9.0)$ & $15.8(13.2-18.8)$ & $0.001^{\mathrm{b}}$ \\
\hline $4-5$ members & $40.6(36.8-44.4)$ & $53.9(50.0-57.7)$ & \\
\hline 6 members or more & $52.6(48.8-56.5)$ & $30.3(26.9-34.0)$ & \\
\hline
\end{tabular}

Of the insured respondents, $50.9 \%, 48.3 \%, 29.6 \%, 27.7 \%$ and $17.0 \%$ reported having problem of "anxiety or depression", "pain and discomfort", "usual activities", "mobility" and "self-care" respectively (Figure 1). However, a significant difference was found between the insured and uninsured population in case of "mobility" ( $p=0.002)$, "self-care" $(p=0.000)$, "pain and discomfort" $(p=0.005)$.

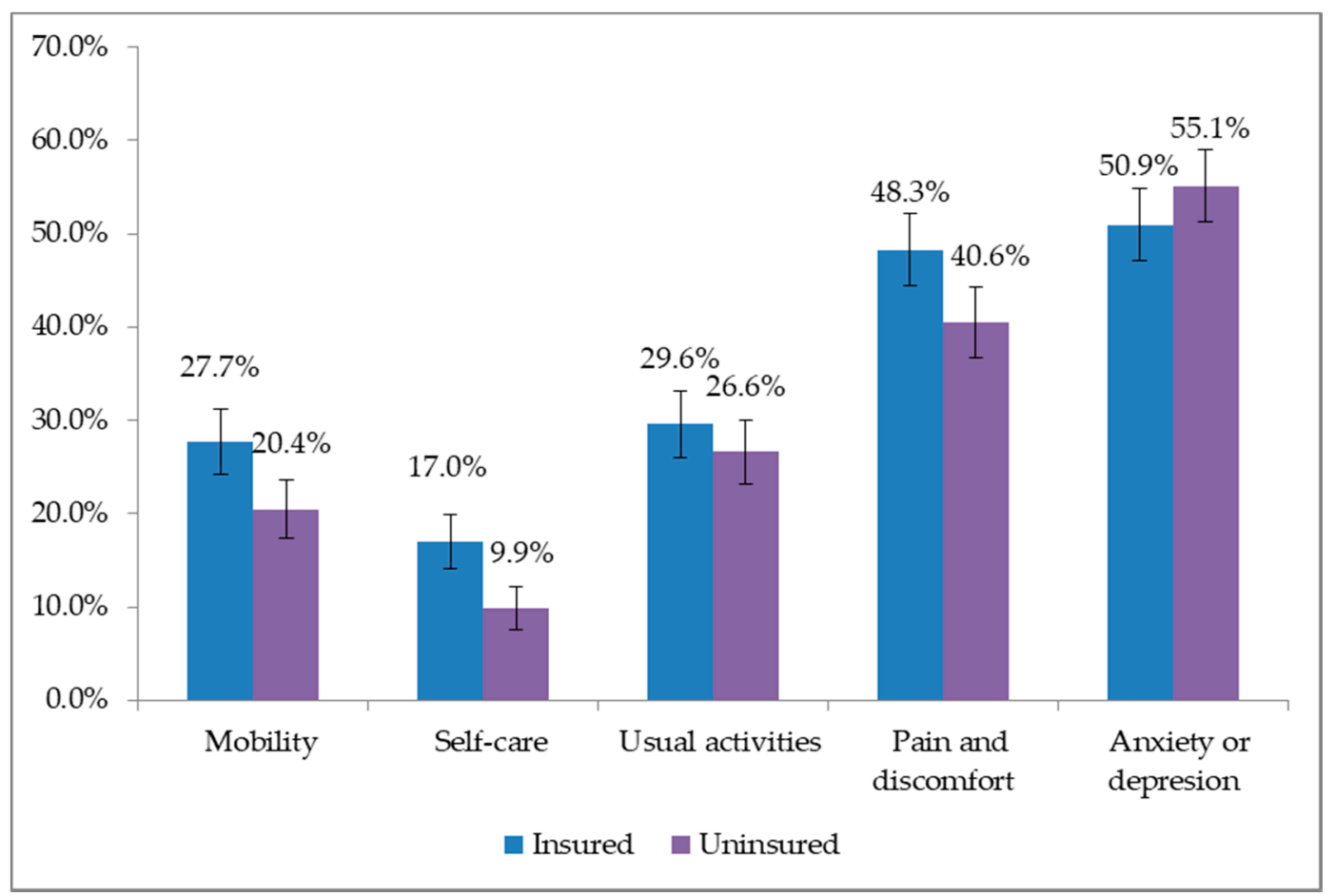

Figure 1. Proportion reported problem in EQ-5D dimensions between insured and uninsured.

Table 3 reports the health status and self-reported illness in terms of EQ-5D dimensions among the insured and uninsured respondents. The mean EQ-5D score was significantly different $(p=0.003)$ between the two groups. The mean VAS score for the uninsured group $(77.3 ; 95 \% \mathrm{CI}=75.9-78.7)$ was higher than that of the insured group $(77.0 ; 95 \% \mathrm{CI}=75.5-78.5)$ although the difference was not statistically significant. 
Table 3. Health status (EQ-5D and VAS score) and self-reported illness between insured and uninsured.

\begin{tabular}{cccc}
\hline \multirow{2}{*}{ Characteristics } & Insured & Uninsured & \multirow{2}{*}{$p$-Value } \\
\cline { 2 - 3 } & $\mathbf{\% ~ ( 9 5 \% ~ C I )}$ & $\mathbf{\% ~ ( 9 5 \% ~ C I ) ~}$ & \\
\hline EQ-5D mean score & $0.704(0.682-0.727)$ & $0.749(0.730-0.769)$ & 0.003 \\
EQ-5D median score & 0.726 & 0.766 & \\
\hline VAS (mean score) & $77.0(75.5-78.5)$ & $77.3(75.9-78.7)$ & 0.783 \\
VAS (Median score) & 80.0 & 80.0 & \\
\hline Self-reported chronic illness/symptoms & $9.8(7.5-12.0)$ & $7.6(5.5-9.6)$ & 0.166 \\
\hline
\end{tabular}

The logistic regression analysis showed the association between the CBHI enrollment and dimensions of the EQ-5D (Table 4). We found that individuals having problems in "mobility" $(\mathrm{OR}=1.65 ; 95 \% \mathrm{CI}: 1.25-2.17)$, "self-care" (OR = 2.29; 95\% CI: 1.62-3.25) and "pain and discomfort" $(\mathrm{OR}=1.43$; 95\% CI: 1.13-1.81) were more likely to enroll in the CBHI scheme than individuals having no such problems. The households with 4 to 5 members and more than 6 members were significantly more likely to enroll in the CBHI scheme compared to the households with fewer than 4 members in all five models.

Table 4. Association between EQ-5D dimensions and CBHI enrollment.

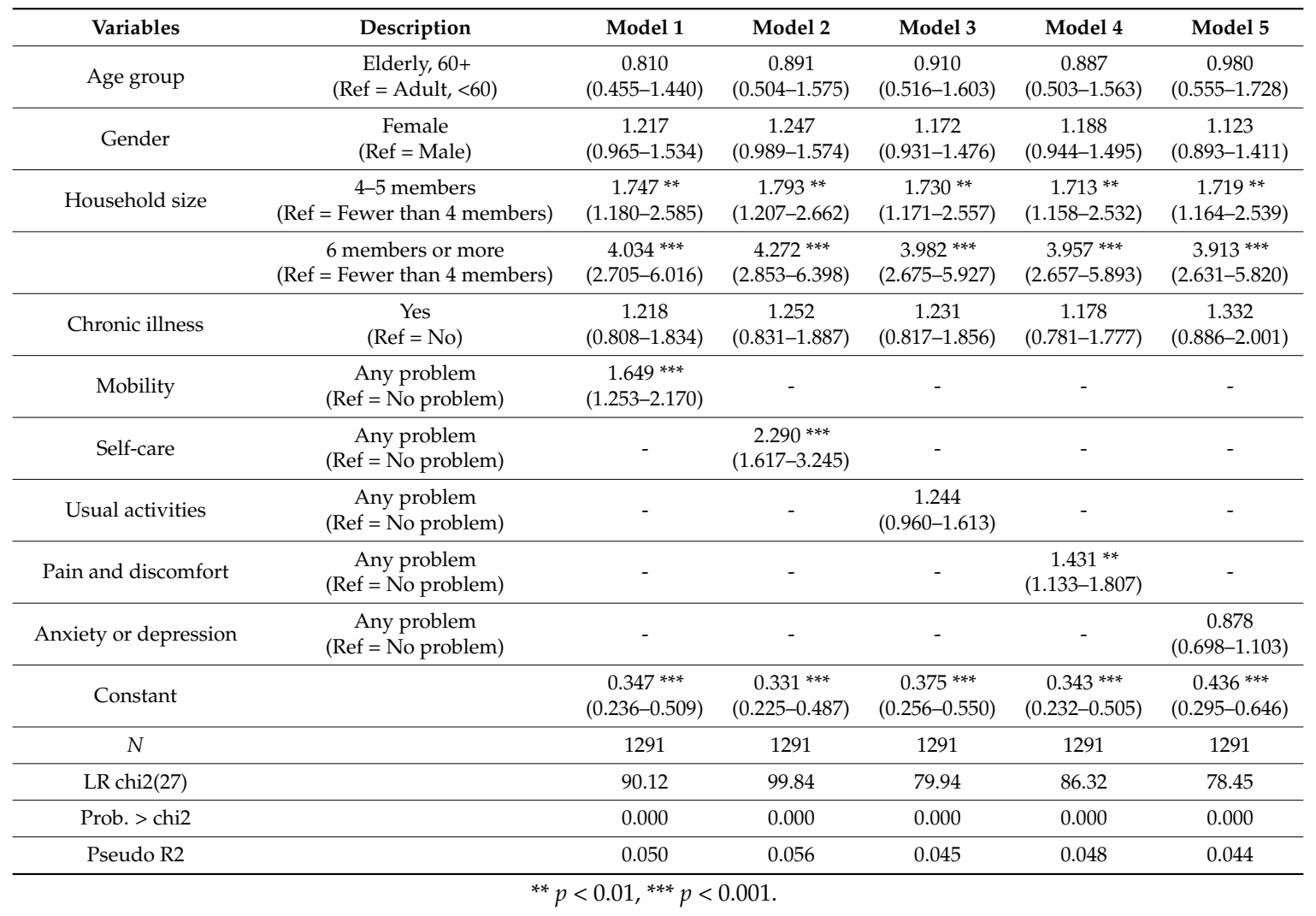

In model 6, CBHI scheme enrollment was regressed with the EQ-5D scores of individuals along with other background characteristics (Table 5). The odds ratio for the EQ-5D score is 0.46 (95\% CI: $0.31,0.69$ ). This implies individuals with higher EQ-5D scores (a higher score refers to better health) were less likely to enroll in CBHI scheme. 
Table 5. Association between EQ-5D score and CBHI enrollment.

\begin{tabular}{ccc}
\hline Variables & Description & $\begin{array}{c}\text { Model 6 (Dependent }=\text { CBHI Enrollment; } \\
\mathbf{1}= \\
\text { Insured, } \mathbf{0}=\text { Uninsured) } \\
\text { Odds Ratio (95\% CI) }\end{array}$ \\
\hline Age group & Elderly, 60+ (Ref $=$ Adult,$<60)$ & $0.861(0.488-1.518)$ \\
Gender & Female $($ Ref $=$ Male) & $1.196(0.950-1.506)$ \\
Household size & $4-5$ members (Ref $\leq 4$ members) & $1.736^{* *}(1.173-2.570)$ \\
Chronic illness & $\geq 6$ members (Ref $\leq 4$ members) & $4.049^{* * *}(2.715-6.040)$ \\
Eq-5D score & Yes (Ref $=$ No) & $1.164(0.771-1.757)$ \\
Constant & & $0.460 * *(0.307-0.689)$ \\
$N$ & & $0.711(0.444-1.137)$ \\
LR chi2(27) & & 1291 \\
Prob. $>$ chi2 & & -848.9 \\
Pseudo R2 & & 0.000 \\
\hline
\end{tabular}

${ }^{* *} p<0.01, * * * p<0.001$

\section{Discussion}

We have observed adverse selection among enrollees of a voluntary CBHI scheme when assessing the association between health status and enrolment. Our descriptive analysis showed that the EQ-5D health status of the insured individuals was significantly lower than matched uninsured individuals. When adjusting for confounding factors with multiple regression models, we found that the individuals with higher EQ-5D scores were about half as likely to enroll in CBHI scheme. It can thus be argued that adverse selection was present in the CBHI scheme. Such a problem can be a threat to the financial sustainability of the scheme. Our findings were similar to a previous study conducted in China, which found the presence of adverse selection in the Rural Mutual Health Care scheme [14]. Unlike our study, the Chinese study applied two questions for assessing the health status of the individuals, which included whether individuals suffered from any illness in the last month before the survey and the severity of that illness. A study in Burkina Faso, however, did not find any association between the health status of the household and CBHI enrollment [18].

We analyzed the relationship between insurance enrolment and five dimensions of health condition, including the physical and mental health status of individuals captured in the EQ-5D instrument. Among the specific health dimensions, three of them ("mobility", "self-care", and "pain and discomfort") had significant association with the enrolment in CBHI scheme. Between the two other health dimensions ("usual activities" and "anxiety or depression"), "usual activities" was not significantly associated with the enrolment to CBHI scheme although it was at the borderline of significance. The odds-ratio of "usual activities" was 1.24 (95\% CI: 0.96-1.61), which could be considered as an indication of higher enrolment of people with a problem in "usual activities". Further, the "anxiety or depression" dimension was not significantly associated with "insurance enrolment". In the context of the CBHI scheme analyzed here, the mental health services were not included in the benefits package and it is possible that it had not been reflected in the enrolment status of the individuals into the scheme.

Several solutions have been undertaken by health policymakers and private health insurance providers to reduce adverse selection in health insurance schemes. For instance, (i) mandatory enrollment of all individuals in the catchment area of the scheme; (ii) increasing the waiting period for accessing healthcare after enrolment in the scheme; (iii) introducing experience ratings or setting different premiums for different risk groups; (iv) cherry picking members or enrolling only low-risk people [14,24]. Many of these approaches may not be appropriate in the context of informal workers in Bangladesh. In general, CBHI schemes are subject to voluntary enrolment and the first remedy, mentioned above, e.g., compulsory enrolment, could not be considered since in the context of this current $\mathrm{CBHI}$ scheme, it is likely that the informal workers do not have a regular and steady income. 
Therefore, it was not imperative to enroll all informal workers and their household members in the scheme. From the beginning of the scheme, a 2-week waiting period for out-patient care and a 4-week period for inpatient care benefits were introduced. These waiting periods might have some effect on reducing the adverse selection. While more extended waiting periods could be a solution for lowering adverse selection, it might appear as a discouraging factor for potential enrollees to join a voluntary insurance scheme.

Introduction of experience ratings also may not be an appropriate way of reducing adverse selection in the context of this CBHI scheme since administering and overseeing the medical condition of potential enrollees would be very costly and might lead to financial challenges for sustainability. Since the income and health risk of potential scheme enrollees were difficult to monitor, the community-rating of the premium might be an appropriate solution for CBHI schemes targeting low-income informal workers. It should be noted here that the fourth way of reducing adverse selection, e.g., cherry picking or ensuring only the low-risk people was inappropriate since the scheme targeted the informal sector workers and their household members and any biases towards low-risk people would result in further inequities.

The conventional remedies of adverse selection appeared to not be applied often in the context of CBHI scheme [9]. In such a situation, we found that enlargement of the pool of members to allow healthy-to-ill cross-subsidization within the scheme enrollees would be a possible way to tackle the financial challenges of this CBHI scheme. However, it might be challenging to accumulate a large pool of members under the CBHI scheme. Khan and Ahmed found in an earlier study that the educational intervention to the informal workers could be a useful tool for increasing willingness to join a CBHI scheme and enlarge the coverage of the scheme [25].

A study conducted in China reported that adverse selection was relatively higher in an insurance scheme when households were partially enrolled (enrolled a few members) compared to fully enrolled (enrolled all members) as the partially enrolled households chose insurance for the members who had worse health status among them [14]. Several studies conducted in Sub-Saharan African settings reported that the obligation to enroll the entire household could reduce adverse selection [26,27]. This might decrease the possibility of enrolling only sick members of the households in the scheme. However, in our study, the benefits package included coverage of up to 6 members of the households with a flat-rate premium and coverage of more household members with an additional premium. Since the average household size of Bangladesh and the study sample were 4.5, our current scheme should have reduced the adverse selection seen with partial household enrolment.

One limitation of the current study was that the EQ-5D information was not collected for all members of households in the insured and uninsured groups for assessing the association between insurance enrollment and health status. However, we collected information from the selected adult wage-earning member of the households who might have influenced the decision making of insurance enrolment of the household. Another limitation is that the findings of this study could not be generalized to the whole country since this study only included a pilot intervention in a single district of Bangladesh.

\section{Conclusions}

This study showed the evidence of adverse selection in a CBHI scheme for informal workers in Bangladesh. The government of Bangladesh adopted the Health Care Financing Strategy 2012-2032 as a plan for achieving Universal Health Coverage where CBHI schemes were considered for securing financial protection of informal sector workers and their household members [8]. Adverse selection can be a challenge for achieving the success with CBHI schemes and consequently, achieving Universal Health Coverage. Adverse selection should thus be considered while designing and scaling up CBHI schemes in Bangladesh and in similar country settings.

Acknowledgments: We thank the Grand Challenge Canada for funding this study. icddr,b acknowledges with gratitude the commitment of Grand Challenge Canada to its research efforts. icddr,b is also thankful to the 
Governments of Bangladesh, Canada, Sweden and the UK for providing core/unrestricted support. Gratitude goes to Khandaker Mohammad Zahid and other field workers for their cordial cooperation for conducting this study. We are thankful to Jorge Martin del Campo of Johns Hopkins University for the language check.

Author Contributions: Sayem Ahmed and Jahangir A. M. Khan conceptualized the study. Sayem Ahmed and Md. Zahid Hasan performed the data analysis and interpretation. Sayem Ahmed, Abdur Razzaque Sarker, Marufa Sultana, Sanchita Chakrovorty, Md. Zahid Hasan, Andrew J. Mirelman and Jahangir A. M. Khan contributed in writing. Jahangir A. M. Khan and Andrew J. Mirelman critically reviewed the final version. All authors approved the final version of the manuscript.

Conflicts of Interest: The authors declare no conflict of interest.

\section{References}

1. Mills, A. Health care systems in low- and middle-income countries. N. Engl. J. Med. 2014, 370, 552-557. [CrossRef] [PubMed]

2. World Health Organization. Global Health Expenditure Database; World Health Organization: Geneva, Switzerland, 2012.

3. World Health Organization. The World Health Report: Health Systems Financing: The Path to Universal Coverage; World Health Organization: Geneva, Switzerland, 2010.

4. Bennett, S. The role of community-based health insurance within the health care financing system: A framework for analysis. Health Policy Plan. 2004, 19, 147-158. [CrossRef] [PubMed]

5. Barasa, E.W.; Mwaura, N.; Rogo, K.; Andrawes, L. Extending voluntary health insurance to the informal sector: Experiences and expectations of the informal sector in Kenya. Wellcome Open Res. 2017, 2, 94. [CrossRef]

6. Khan, J.A.M.; Ahmed, S.; Evans, T.G. Catastrophic healthcare expenditure and poverty related to out-of-pocket payments for healthcare in Bangladesh-An estimation of financial risk protection of universal health coverage. Health Policy Plan. 2017, 1-9. [CrossRef] [PubMed]

7. MoHFW. Bangladesh National Health Accounts 1997-2015; MoHFW: Dhaka, Bangladesh, 2017.

8. MoHFW. Expanding Social Protection for Health: Towards Universal Coverage, Health Care Financing Strategy 2012-2032; MoHFW: Dhaka, Bangladesh, 2012.

9. Parmar, D.; Souares, A.; de Allegri, M.; Savadogo, G.; Sauerborn, R. Adverse selection in a community-based health insurance scheme in rural Africa: Implications for introducing targeted subsidies. BMC Health Serv. Res. 2012, 12, 181. [CrossRef] [PubMed]

10. Donfouet, H.; Mahieu, P.-A. Community-based health insurance and social capital: A review. Health Econ. Rev. 2012, 2, 5. [CrossRef] [PubMed]

11. Ranson, M.K. Reduction of catastrophic health care expenditures by a community-based health insurance scheme in Gujarat, India: Current experiences and challenges. Bull. World Health Organ. 2002, 80, 613-621. [PubMed]

12. Rothschild, M.; Stiglitz, J. Equilibrium in Competitive Insurance Markets: An Essay on the Economics of Imperfect Information Author(s): Equilibrium in competitive insurance markets: An essay on the economics of imperfect information. Source Q. J. Econ. 1976, 90, 629-649. [CrossRef]

13. Resende, M.; Zeidan, R. Adverse selection in the health insurance market: Some empirical evidence. Eur. J. Health Econ. 2010, 11, 413-418. [CrossRef] [PubMed]

14. Wang, H.; Zhang, L.; Yip, W.; Hsiao, W. Adverse selection in a voluntary rural mutual health care health insurance scheme in China. Soc. Sci. Med. 2006, 63, 1236-1245. [CrossRef] [PubMed]

15. Cutler, D.M.; Zeckhauser, R.J. The Anatomy of Health Insurance. In Handbook of Health Economics; Culyer, A.J., Newhouse, J.P., Eds.; Elsevier: Amsterdam, The Netherlands, 2000; pp. 563-637.

16. Noterman, J.P.; Criel, B.; Kegels, G.; Isu, K. A prepayment scheme for hospital care in the Masisi district in Zaire: A critical evaluation. Soc. Sci. Med. 1995, 40, 919-930. [CrossRef]

17. Dror, D.M.; Soriano, E.S.; Lorenzo, M.E.; Sarol, J.N.; Azcuna, R.S.; Koren, R. Field based evidence of enhanced healthcare utilization among persons insured by micro health insurance units in Philippines. Health Policy 2005, 73, 263-271. [CrossRef] [PubMed]

18. De Allegri, M.; Kouyaté, B.; Becher, H.; Gbangou, A.; Pokhrel, S.; Sanon, M. Understanding enrolment in community health insurance in sub-Saharan Africa: A population-based case-Control study in rural Burkina Faso. Bull. World Health Organ. 2006, 84, 852-858. [CrossRef] [PubMed] 
19. Bangladesh Bank. Annual Report 2014-2015; Bangladesh Bank: Dhaka, Bangladesh, 2015; Volume 1.

20. Asian Development Bank. The Informal Sector and Informal Employment in Bangladesh; Asian Development Bank: Manila, Philipines, 2010; ISBN 978-9-29-092923-9.

21. Brooks, R.; Rabin, R.; de Charro, F. The Measurement and Valuation of Health Status Using EQ-5D: A European Perspective: Evidence from the EuroQol BIOMED Research Programme; Brooks, R., Rabin, R., de Charro, F., Eds.; Kluwer Academic Publishers: Dordrecht, The Netherlands, 2003; ISBN 9401702330.

22. Rabin, R.; Charro, F. EQ-SD: A measure of health status from. Ann. Med. 2001, 33, 337-343. [CrossRef] [PubMed]

23. Saleh, F.; Mumu, S.J.; Ara, F.; Hafez, M.A.; Ali, L. Non-adherence to self-care practices \& medication and health related quality of life among patients with type 2 diabetes: A cross-sectional study. BMC Public Health 2014, 14, 431. [CrossRef]

24. Morris, S.; Devlin, N.J.; Parkin, D. Economic Analysis in Health Care, 2nd ed.; John Wiley \& Sons, Ltd.: Chicheste, UK, 2012; ISBN 047001685X.

25. Khan, J.A.M.; Ahmed, S. Impact of educational intervention on willingness-to-pay for health insurance: A study of informal sector workers in urban Bangladesh. Health Econ. Rev. 2013, 3, 12. [CrossRef] [PubMed]

26. Schneider, P.; Diop, F. Community-Based Health Insurance in Rwanda. In Health Financing for Poor People: Resource Mobilization and Risk Sharing; Preker, A.S., Carrin, G., Eds.; The World Bank: Washington, DC, USA, 2005; pp. 251-272.

27. Jütting, J. Do community-based health insurance schemes improve poor people's access to health care? Evidence from rural Senegal. World Dev. 2003, 32, 273-288. [CrossRef]

(C) 2018 by the authors. Licensee MDPI, Basel, Switzerland. This article is an open access article distributed under the terms and conditions of the Creative Commons Attribution (CC BY) license (http:/ / creativecommons.org/licenses/by/4.0/). 